\title{
ELECTROPHORETIC BANDING PATTERN OF ESTERASE ISOZYME IN DIFFERENT TISSUES OF PUNTIUS SOPHORE (CYPRINIDAE : CYPRINIFORMES)
}

\author{
HAWA JAHAN ${ }^{1}$, PARTHA SARATHI GOPE ${ }^{2}$, \\ MOHAMMAD SHAMIMUL ALAM ${ }^{1}$, REZA MD. SHAHJAHAN ${ }^{1 *}$ \\ ${ }^{1}$ Department of Zoology, University of Dhaka, Dhaka-1000, Bangladesh \\ ${ }^{2}$ Department of Zoology, University of Dhaka and International Centre for \\ Diarrhoeal Disease Research, Bangladesh
}

\begin{abstract}
Esterase isozyme of different tissues of Puntius sophore was analyzed using $7.5 \%$ polyacrylamide gel electrophoresis (PAGE). Fish specimens were collected from local market. The tissues used were taken from different muscles, stomach, fore-, mid- and hind-gut, liver, eyes, gill, heart, kidney, fore-, mid- and hind- brain, eggs and ovary. Six different esterase bands were detected, named Est-1, Est-2, Est-3, Est-4, Est-5 and Est-6 and their relative mobility were $1.0,0.84,0.62,0.33,0.26$ and 0.13 respectively, each of them representing a single allele. The highest esterase activity was found in liver, followed by gill, kidney, heart, brain, intestine, stomach, eye, reproductive organ and skeletal muscles as detected in the staining intensity. Staining intensity of Est- 4 and Est-5 was higher and Est-6 was the least stained in all the tissues.
\end{abstract}

Key words: Esterase, Isozymes, PAGE, Puntius sophore

\section{Introduction}

Puntius sophore, belonging to the family Cyprinidae, is the most common among captured fishes (Rahman 2005) in Bangladesh. It is easily cultivable (Kohinoor 2000), highly demanding, cheap and considered to be one of the main protein source for low income group. It has high nutritional value, containing $19.0 \mathrm{~g}$ of protein, $37 \mu \mathrm{g}$ of vitamin-A, 1,059 mg of calcium, and other micro nutrients per $100 \mathrm{~g}$ of fish (Thilsted et al. 1997). The residual effect of pesticides on fish is high and they reduce the survival, growth and reproduction of fish (McKim et al. 1975) even cause a significant mortality (Nishat and Choudhury 1985). Besides, pesticides can be accumulated in the fish muscles which are consumed by human causing serious diseases ultimately.

In Bangladesh, industries are situated on the bank of the rivers and dispose organic, inorganic wastes and biohazards on to them in an untreated form. Moreover, pesticides used in the agriculture wash out into these rivers polluting the aquatic environment. Esterases are reported to be associated with pesticide resistance. So, it may be hypothesized that those fishes which are alive in the polluted environment might have

*Corresponding author: E-mail: hawajahan@du.ac.bd 
higher resistance to pesticides and higher accumulation of the chemicals treated as pesticides. Thus, resistance status, as well as, nature of pollution in the aquatic body, could have relation to amount of esterases produced in the body of fish and other aquatic organisms.

Several toxicity tests on different agro-chemicals were done on P. sophore (Prabhuji et al. 1983) and other species of Puntius (Gill et al. 1990). Esterases are multifunctional, lipid hydrolyzing enzymes occurring in multiple forms and capable of separation by electrophoresis (King 1974). Isozyme analysis was used to estimate the genetic distance between different populations and the variability of isozyme was also used to devise the genetic sexing system (Shahjahan 1988). Esterases are reported to be involved in regulation of juvenile hormone levels (Kort and Granger 1981), reproduction (Richmond et al. 1980), functioning of nervous system and development of resistance to insecticides (Karunaratne et al. 1999). It may be used as bio-indicators to monitor pollutants in the environment (Vanda et al. 2003). So, in the present study, different forms of esterases found in different tissues of Puntius sophore were analyzed.

\section{Materials and Methods}

Sample collection: $P$. sophore (punti) were brought from Fokirapool and Jatrabari fish market, Dhaka, during January to April 2006. Procurement was made from selected fishermen who directly catch fish from the river Meghna. Collections were made early in the morning in polythene bags with sufficient ice, with no preservatives and transported to Laboratory of Genetics and Molecular Biology, Department of Zoology, University of Dhaka. These were identified following relevant literature (Rahman 2005) and stored in refrigerator at $-80^{\circ} \mathrm{C}$.

Sample preparation: Female P. sophore was dissected and around $15 \mathrm{mg}$ of twenty different tissues were collected: 1. Anterior neck muscle (white), 2. Mid-body muscle (white), 3. Tail muscle (anal region, white), 4. Tail muscle $_{2}$ (Tip-spotted portion, red), 5. Buccal muscle (white), 6. Stomach, 7. Intestine ${ }_{1}$ (fore-gut), 8. Intestine 2 (mid-gut), 9. Intestine $_{3}$ (hind-gut), 10. Liver, 11. Eye (lence), 12. Eye ball (entire, except- lence), 13. Gills, $\left(3^{\text {rd }}\right)$ 14. Heart, 15. Kidney, 16. Fore-brain, 17. Mid-brain, 18. Hind-brain, 19. Eggs and 20. Ovary. Each of the above tissues was squashed in a labeled eppendorf tube in 40 $\mu \mathrm{l}$ of TBE buffer, vortexed for $1 \mathrm{~min} .40 \mu \mathrm{l}$ of bromophenol blue (marker) was added and finally centrifuged at $13,000 \mathrm{rpm}$ for $12 \mathrm{~min}$. The samples were then subjected to electrophoresis and were always put on ice to ensure cold temperature.

The extraction was repeated with selected tissue samples (viz. muscle, stomach, intestine, liver, eye, gill, heart, kidney, brain and reproductive organ) and aliquots of extracts from each of the tissues (without marker) were subjected to Lowry test to quantify the amount of total protein in each of the extract. Rest of the aliquots from each tissue extract was mixed with an equal amount of bromophenol blue and the samples 
were loaded to gel slot such a way that each slot receive an equal amount of protein i.e. each sample contained an equal amount of protein extract and these were subjected to electrophoresis.

Polyacrylamide Gel Electrophoresis: Electrophoresis was conducted on 7.5\% PAGE prepared following Standard method (Hames 1986). An initial pre-run was made at 100 $\mathrm{V}$ for $30 \mathrm{~min}$. which followed another $\sim 1$ hour and $45 \mathrm{~min}$. run after loading $10 \mu \mathrm{l}$ of samples on to the gel. The run was stopped when the markers came to the bottom and the gel was put onto freshly prepared staining mixture $(0.2 \mathrm{M}$ Monobasic sodium phosphate $\left(\mathrm{NaH}_{2} \mathrm{PO}_{4}\right) 1.32 \mathrm{~g}, 0.2 \mathrm{M}$ Dibasic sodium phosphate $\left(\mathrm{Na}_{2} \mathrm{HPO}_{4}\right) 0.5362 \mathrm{~g}$, $\alpha$-napthyl acetate, dissolved in acetone at room temperature. Afterwards the solution was out poured and the gel was incubated in the Fast blue RR solution $(29 / 120 \mathrm{ml})$ at $37^{\circ} \mathrm{C}$ for 25 minutes.

Photography and scoring of bands: The gel was photographed using a digital zoom lense camera (Sony Cybershot, DSC-F88), putting the gel on a white background. Positive and negative poles were marked and bands were numbered as per recommendations of the Standard Committee for Enzyme (Webb 1964). Relative mobility was calculated considering the value of the band with highest mobility as 1 .

\section{Results and Discussion}

Altogether six esterase bands were detected in the 20 different tissues of $P$. sophore, depending on their relative mobility (Fig. 1). These were numbered: Est-1, Est-2, Est-3, Est-4, Est-5 and Est-6. All six esterase bands were not present in each tissue. Since the differentiation of the esterases of various tissues of $P$. sophore was done according to their substrate preference, as they hydrolyze the substrate $\alpha$-naphthyl acetate and produced black colouration. Therefore, all of the above six esterases could be commonly named as $\alpha$-esterase (Vanda et al. 2003). The highest relative mobility value of esterase was $1.0( \pm 0.04)$, possessed by Est-1, located near the $(+)$ pole and it runs $4.5 \mathrm{~cm}$. The relative mobility of Est-2, Est-3, Est- 4 and Est-5 was $0.84( \pm 0.04), 0.62( \pm 0.04), 0.33( \pm$ $0.02)$, and $0.26( \pm 0.02)$, respectively. Est- 6 with the slowest relative mobility, valued $0.13( \pm 0.02$ ), was found near the (-) pole (Fig. 1). Presence of more than two bands is not artifactual (Raymond et al. 1996) and each band corresponds to one allele as per Mendelian inheritance studies (Stordeur 1976). The esterase activity of the different bands obtained from different tissues was arbitrarily measured based on eye estimation of staining intensity, categorized into deep stained (DS), medium deep stained (MDS) and faint stained (FS). The results made for the various esterase bands from twenty different tissues were as follows: 
Muscles: Anterior neck muscle (white), mid-body muscle (white), anal region of tail muscle and spotted portion of tail muscle were examined and all of the muscle tissues showed two faint esterase bands (Est-4 and Est-5) (Fig. 1).

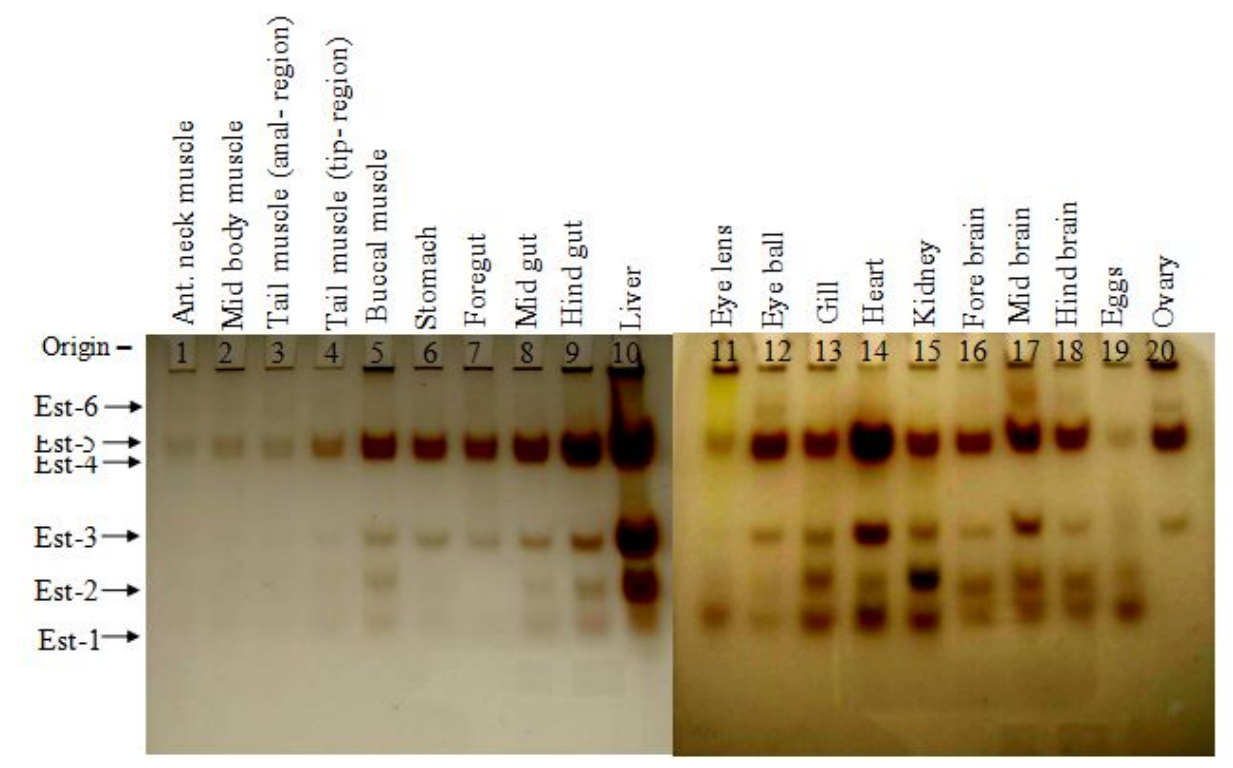

Fig. 1. Electrophoretic banding pattern of esterases of different tissues of P. sophore [Lane 1-20):

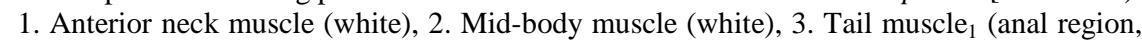
white) 4. Tail muscle ${ }_{2}$ (Tip-spotted portion)(red) 5. Buccal muscle (white), 6. Stomach 7.

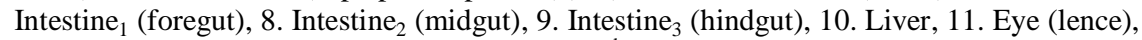
12. Eye ball (entire, except- lence), 13. Gills, $\left(3^{\text {rd }}\right) 14$. Heart, 15. Kidney 16. Fore brain, 17. Mid brain, 18. Hind brain, 19. Eggs, 20. Ovary]. Arrows indicate position of esterase and the relative mobility $(\mathrm{RM})$.

Buccal region: Est-1, Est-2, Est-3, Est-4 and Est-5 were the five bands observed in the muscle of buccal region. Among the five esterase bands Est-4 and Est-5 were deeply stained and the rest of the bands were faintly stained.

Stomach: Three esterase bands (Est-3, Est-4 and Est-5) were found in the stomach.

Intestine (gut): In the foregut three esterase bands viz. Est-3, Est-4 and Est-5 were observed where Est-3 was faintly and Est-4 and Est-5 were deeply stained. Both mid-and hind-gut showed five esterase bands. In both midgut and hindgut Est-1 and Est-2 were faintly stained and Est-3 was medium deep stained and Est-4 and Est-5 were deeply stained. 
Liver: Altogether five esterase bands (Est-1, Est-2, Est-3, Est-4 and Est-5) were found and all of the bands were deeply stained except Est-1.

Eye: Three faintly stained esterase bands (Est-1, Est-3 and Est-4) were observed in the lens of eye. However, in the ball of eye five esterase bands namely Est-1, Est-3, Est-4, Est-5 and Est- 6 were found in the eye ball where Est-1 and Est- 6 showed faintly stained band. Est-3 band was medium deep.

Gill: Est-1, Est-2, Est-3, Est-4 and Est-5 were the five esterase bands found in the $3^{\text {rd }}$ gill and all the bands were deeply stained.

Heart: Five esterase bands (Est-1, Est-2, Est-3, Est-4 and Est-5) were recorded in the heart where all the bands were deeply stained except Est-2.

Kidney: Altogether five deeply stained esterase bands (viz. Est-1, Est-2, Est-3, Est-4 and Est-5) were found in the kidney.

Brain: Five esterase bands (Est-1, Est-2, Est-3, Est-4 and Est-5) were found in both foreand hind-brain where Est-1, Est-2 and Est-3 were faintly stained. In the mid brain all mentioned six esterase bands were observed and Est- 6 was faintly stained. Est-1, Est-2 and Est-3 were faintly and Est-4 and Est-5 were deeply stained in all of the three parts of the brain.

Eggs: Est-1, Est-2, Est-4 and Est-5 were the four faintly stained esterase bands found in eggs.

Ovary: Altogether four esterase bands (viz. Est-3, Est-4, Est-5 and Est-6) were found in the ovary .

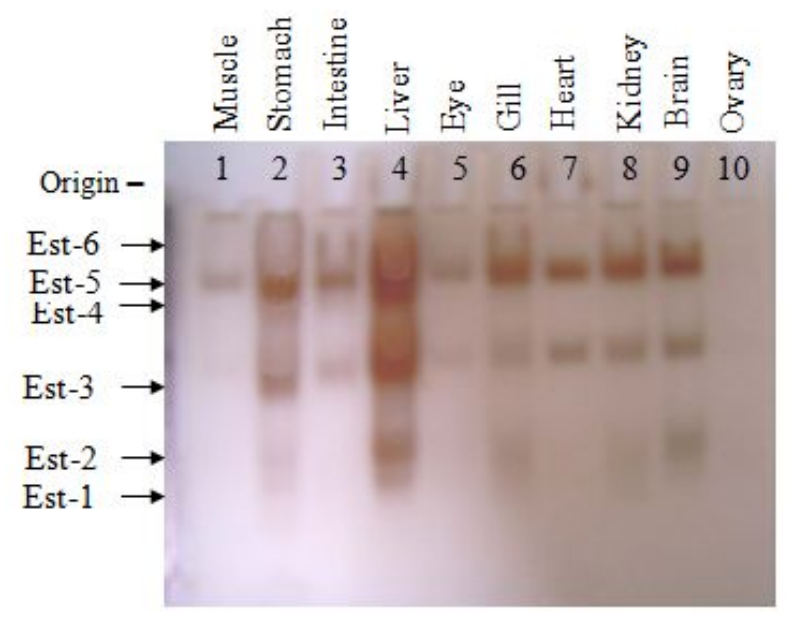

Fig. 2. Proportionately loaded after protein test. Lane 1-10: 1-Muscle, 2-Stomach, 3-Intestine, 4-Liver, 5-Eye, 6-Gill, 7-Heart, 8-Kidney, 9-Brain and 10-Reproductive organ. 
However, according to staining intensity esterase activity in different tissues could be arranged as ascending order: Liver $>$ gill $>$ kidney $>$ heart $>$ brain $>$ Intestine $>$ stomach $>$ eye $>$ reproductive organ $>$ skeletal muscles. Frequency of occurance of various esterase bands was compared in all the tissues and it was revealed that, the maximum frequency of esterase was observed for Est-4 and Est-5 and the minimum frequency was found for Est-6 (Figs. 1-3). Loading equal amount of total protein extracted from different tissues also supported the fact that expression of esterase in $P$. shophore was tissue specific in general (Fig. 2), because the bands maintained the similar order of variable staining intensity (viz. Liver $>$ stomach $>$ gill $>$ kidney $>$ heart $>$ brain $>$ Intestine $>$ eye $>$ reproductive organ $>$ skeletal muscles) except stomach and those were not influenced by the procedure of extraction.

As regards the occurance of number of esterase bands order of organs are as follows: six esterase bands in mid brain; five bands in buccal region, midgut, hindgut, liver, gill, eye ball, heart, kidney, fore brain and hind brain; four bands in egg, ovary; three bands in stomach, foregut, lens of eye; two esterase bands in anterior neck muscle, mid-body muscle and tail muscle.

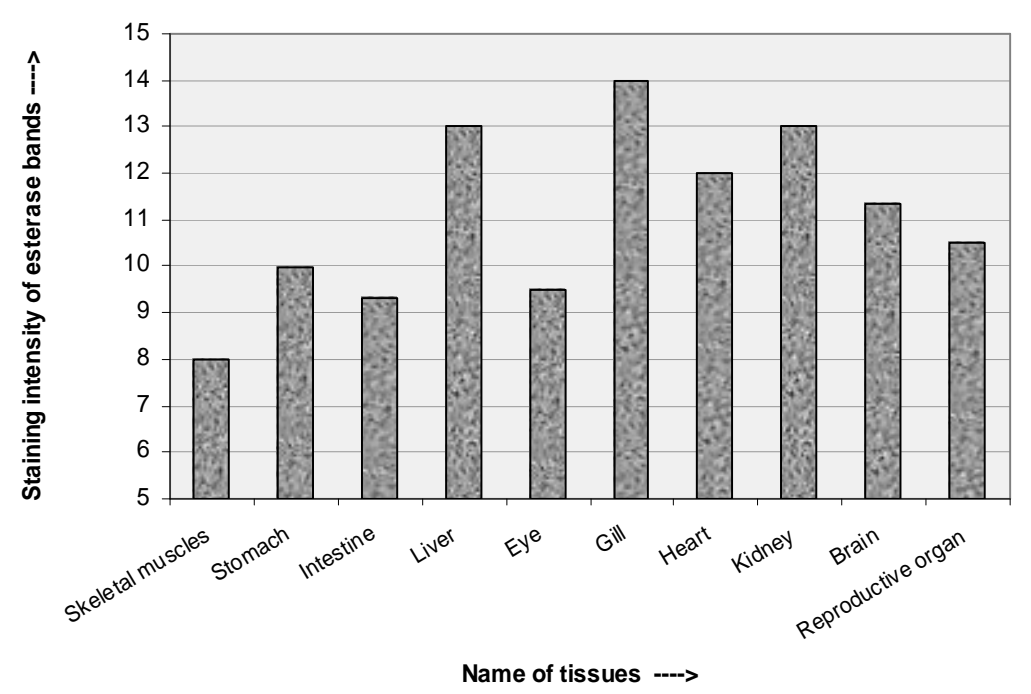

Fig.3. Comparative analysis of staining intensity of esterase bands of various tissues of Puntius sophore.

During the present study higher band intensity (deep stained bands) was observed in the tissues of digestive system more specifically liver and intestine. In $1997 \mathrm{Li}$ and Fan made similar observation in the tissues of different body parts of several fishes viz- topmouth 
gudgeon (Pseudorasbora parva), goldfish (Carassius auratus), nile tilapia (Tilapia nilotica), mosquitofish (Gambusia affinis) and rainbow trout (Salmo gairdneri). But the absence of enzyme activity in the gill of the mentioned species was quite different from the present study.

Eight esterase bands were found in different tissues (brain, eye, heart, muscle and liver) of Orechromis aureus (Hongtuo et al. 1993). Six esterase zones were found in the brain of channel catfish Ictalurus punctatus (Knowles et al. 1968). Seven esterase isozymes were observed in four populations of blunt snout from three lakes and one river (Sifa et al. 1993). In the present study, six esterase isozymes were recorded in punti (Fig. 1).

As previously reported (Gunning et al. 1998, Manwell et al. 1968 and Vanda et al. 2003), tissue specific distribution and intensity correlates pesticides residue and pollutants in the dwelling environment; an intensive study of different esterase band index of different species of Puntius and related fish in different cultural area would provide a potential input in the management tactics.

\section{References}

Gill, T.S., J. Pande and H. Tewari. 1990. Sublethal effects of an organophosphorus insecticide on certain metabolite levels in a freshwater fish, Puntius conchonius Hamilton. Pestic. Biochem. Physiol. 36: 290-299

Gunning, R.V., G.D. Moores and A.L. Devonshire. 1998. Insensitive acetylcholinesterase and resistance to organophosphates in Australian Helicoverpa armigera. Pestic. Biochem. Physiol. 62: 147-151.

Hames, B.D. 1986. An introduction to Polyacrylamide gel electrophoresis. In Gel electrophoresis of proteins. D. Rickwood and B.D. Hames (Ed.). RIL Press Limited. Oxford. Washington, D. C. pp. 1-45.

Hongtuo, F., D. Zin D and Tingting. 1993. Isozyme of Oreochromis aureus. Aquaculture. 111: 326.

Karunaratne, S.H.P.P., G.J. Small and J. Hemingway. 1999. Characterization of the elevated esterases associated insecticide resistance mechanisms in Nilaparvata lugens (Stal) and other planthopper species. Int. J. Pest Manag. 45(3): 225-230.

Khangarot, B.S. and P.K. Ray. 1988. The acute toxicity of silver to some freshwater fishes. Acta. Hydrochim. Hydrobiol. 16(5): 541-545.

King R.C. 1974. A dictionary of genetics. pp. 156. Oxford University Press, Inc.

Knowles, C.O., S.K. Arurkar and J.W. Hogan. 1968. Electrophoretic separation of fish brain esterase. J. Fish Res. Bd. Can. 25.

Kohinoor, A.H.M. 2000. Development of culture technology of three small indegenous fishmola (Amblypharyngodon mola), punti (Puntius sophore), and Chela (Chela cachius) with notes on some aspects of their biology. Ph.D. Thesis, Department of Fisheries Management, Bangladesh Agricultural University, Mymensingh.

Kort, C.A. and N.A. Granger 1981. Regulation of the juvenile hormone titer. Ann. Rev. Entomol 26: $1-28$.

Li, S.N. and D. F. Fan. 1997. Activity of esterases from different tissues of freshwater fish and responses of their isoenzymes to inhibitors. J. Toxic. Environ. Health. 51(2): 149-157.

Manwell, C. and C.M.A. Baker. 1968. Genetic variation of iso-citrate, malate and 6phosphogluconate dehydrogenase in snails of the genus Cepaea - introgressive hybridization, polymorphism and pollution? Comp. Biochem. Physiol. 26: 195-209. 
Mckim, J.M., D.A. Benoit, K.K. Biesinger, W.A. Brungs and R.E. Siefert. 1975. Effects of pollution on fresh water fish. J. Wat. Pollut. Contr. Fed. 47: 1711-1764.

Nishat, A. and S.K. Choudhury. 1985. Water Quality: Problems and Needs for Integrated Control in Bangladesh, paper presented at a Regional Seminar on Water resources Policy in Agro-Socio-Economic Development, Dhaka.

Prabhuji, S.K., G.C. Srivastava, S.J.H. Rizvi and S.N. Mathur. 1983. 1,3,7-Trimethylxanthine (caffeine); a new natural fish fungicide. Cellular and Molecular Life Sciences. 39(2): 177 -179 .

Rahman, A.K.A. 2005. Freshwater fishes of Bangladesh. 2nd. Zoological Society of Bangladesh. Department of Zoology, University of Dhaka. pp. 1-25, 150-152.

Raymond, M.C.L. Qiao and A. Callaghan. 1996. Esterase polymorphism in insecticide susceptible populations of the mosquito Culex pipiens. Genet. Res. 67: 19-26.

Richmond, R.C., D.G. Gilbert, K.B. Sheehan, M.H. Gromko and F.M. Butterworth. 1980. Esterase 6 and reproduction in Drosophila melanogaster. Science. 207: 1483-1485.

Shahjahan, R.M. 1988. Laboratory studies detected towards the development of a genetic sexing technique in Mediterranean fruit fly Ceratitis capitata. Ph.D. Thesis. Univ. Manchester, U.K. pp. 198.

Sifa, L., C. Wanqi and Z. Biyun. 1993. Variation of morphology and biochemical genetic markers among population of blunt snout bream (Megalobrama mblycephala) Aquaculture. 111: 117-127.

Stordeur, D. 1976. Esterase in the mosquito Culex pipiens pipiens L.: formal genetics and polymorphism of adult esterases. Bioch. Genetics. 14: 481-493.

Thilsted, S.H., N. Roos and N. Hasan. 1997. The role of small indigenous fish species in food and nutrition security in Bangladesh. NAGA News letter. pp.13.

Vanda, M.D.C., R.M. Marques, A.S. Lapenta and M.F.P.S. Machado. 2003. Functional classification of esterases from leaves of Aspidosperma polyneuron M. Arg. (Apocynaceae). Genet. Mol. Biol. 26: 2.

Webb, E.C. 1964. Nomenclature for multiple enzyme forms. Nature. 203: 821. 